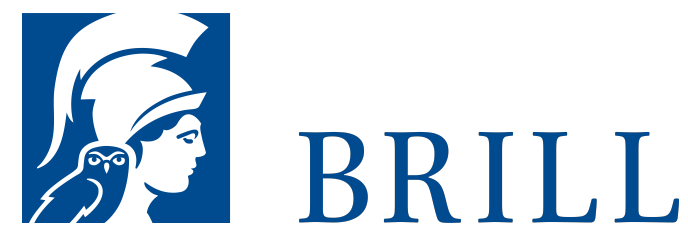

\title{
Wahrheit, Zeit und Freiheit
}

Einführung in eine philosophische Theorie

Author: Anton F Koch

In einer Reflexion auf das Faktum, dass wir in unseren Urteilen Wahrheitsansprüche erheben, werden allgemeine Voraussetzungen unserer Urteilspraxis entwickelt und gerechtfertigt. Dabei zeigt sich, dass Wahrheit drei Aspekte hat: einen phänomenalen, einen realistischen und einen pragmatischen Aspekt (Wahrheit als Unverborgenheit, als Korrespondenz und als berechtigte Behauptbarkeit). Ferner wird gezeigt, dass ein materielles Raum-Zeit-System nur möglich ist, wenn in ihm Subjektivität, als Pluralität von Personen, vorkommt. Auf dem Boden dieser Subjektivitätsthese werden die Aspekte der Wahrheit mit den drei Dimensionen des Raumes und den drei Ekstasen der Zeit (Zukunft, Gegenwart und Vergangenheit) verknüpft und es wird gezeigt, dass die Zeit objektiv ausgerichtet ist (einen „Pfeil“ besitzt), weil freie Akteure existieren. Da deren Freiheit mit dem Determinismus inkompatibel ist und da weder jene noch dieser preisgegeben werden kann, wird eine metakompatibilistische Freiheitstheorie entwickelt, mittels deren Wahrheit, Zeit und Freiheit widerspruchsfrei aufeinander bezogen werden können.

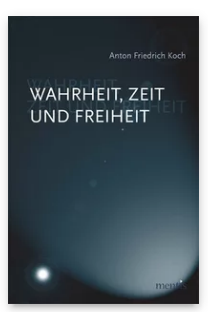

Pages: 188

Seiten

Language:

German

Subjects: 19 th \& 2oth Century

Philosophy, Philosophy

Publisher: Brill| mentis

E-Book (PDF)

Released online: o1 Jul 2006

ISBN: 978-395743-926-о

Paperback

Publication date: o1 Jul 2006 ISBN: 978-389785-601-1 List price USD $\$ 52.00$ 
For more information see brill.com

Order information: Order online at brill.com +44330 333 0049 | customerservices@brill.com Submission information: brill.com/authors

Titles published by Brill | Fink, Brill | mentis or Brill | Schöningh: +49(o)715413279216| brill@brocom.de 